Р. В. Трембовецька, к.т.н., доцент,

В. Я. Гальченко, д.m.н., професор,

В. В. Тичков, к.т.н., доцент,

А. В. Сторчак, аспірант

Черкаський державний технологічний університет

б-р Шевченка, 460, м. Черкаси, 18006, Україна

\title{
ОЦІНКА ТОЧНОСТІ НЕЙРОМЕРЕЖЕВИХ МЕТАМОДЕЛЕЙ КРУГОВИХ НАКЛАДНИХ ВИХРОСТРУМОВИХ ПЕРЕТВОРЮВАЧІВ
}

Для задачі синтезу вихрострумового перетворювача із однорідною зоною чутливості створені його RBF-метамоделі, які мають високу обчислювальну ефективність. Дані метамоделі можна використовувати для проектування перетворювача із заданим розподілом густини вихрових струмів в контрольних точках простору, щя розташовані на поверхні струмопровідного об'єкту в зоні контролю перетворювача. Котушка збудження концентричного накладного вихрострумового перетворювача представлена витком, щяо живиться змінним струмом та який розташований над об'єктом контролю з постійними електрофізичними параметрами. Отримані метамоделі перевірені на адекватність та інформативність за комплексом статистичних показників з об'єктивною оцінкою їх статистичної значущості. При апроксимації поверхні відгуку використовувався комп'ютерний план експерименту, а саме багатовимірний простір пошуку заповнювався точками, які згенеровані за допомогою ЛП т-послідовностей, що рівномірно розташовані на поверхні відгуку. Перевірено відтворюваність поверхні відгуку за допомогою отриманої метамоделі в усій області моделювання. Досягнута прийнятна похибка апроксимації.

Ключові слова: метамодель, апроксимачія поверхні відгуку, нейронна мережа, комп'ютерний план експерименту, адекватність метамоделі, інформативність метамоделі, вихрострумовий перетворювач, котушка збудження, густина вихрових струмів.

Вступ та аналіз останніх досліджень. Накладні вихрострумові перетворювачі (НВСП) класичних конструкцій мають ряд недоліків, один із яких - нерівномірна чутливість. На етапі проектування він частково усувається створенням нестандартної конструкції, як то сукупності збуджувальних котушок 3 певним їх розташуванням та схемою включення. Серед можливих конструкцій системи збудження виділяють гомогенні та гетерогенні структури збудження НВСП. Гомогенні структури містять систему тільки кругових витків із радіусами $r_{0 i}$ або тільки систему витків у вигляді рамок розмірами $a x b$ із різним розташуванням відносно об'єкта контролю (ОК). Наприклад, рамка розташована паралельно до ОК або перпендикулярно, тоді як гетерогенні структури складаються із різних типів витків, як кругових так і рамкових, та різноманітного їх розташування один відносно іншого. Геометричні моделі структур збу- дження у вигляді кругових витків розглянуто в роботі [1].

Застосуванням гомогенних та гетерогенних структур збудження із відповідною схемою включення досягається зменшення неоднорідності розподілу густини вихрових струмів (ГВС) та збільшення чутливості вихрострумового методу контролю. У результаті ці структури генерують максимально наближений до ідеального однорідний розподіл ГВС на поверхні ОК. Створення такої нестандартної конструкції системи збудження НВСП є проектною задачею, яку доцільно вирішувати із застосуванням оптимального синтезу.

Функція цілі оберненої задачі в оптимізаційній постановці задається класично у вигляді квадрата відхилення між модулем ГВС у контрольній точці ОК з номером $i$, створеним відповідною $k$-ю котушкою системи збудження НВСП $J_{i k}$, та бажаним значенням модуля 
ГВС у контрольній точці $J_{\text {reference. }}$ Надалі ця функція мінімізується. Для синтезу НВСП застосування традиційного підходу є недоцільним і неможливим через суттєву складність реалізації обчислювального процесу, що відповідно впливає на надзвичайно велику тривалість розв'язання задачі.

Так, розрахунок розподілу ГВС $J_{i k}$ за математичною моделлю [2-4], яка отримана рішенням прямої задачі електродинаміки у вигляді диференціальних рівнянь Максвела, становить від 5 до 20 годин залежно від форми витка та його розмірів [5]. Безсумнівно, що велика ресурсоємність не дозволяє реалізувати оптимальний синтез в його традиційному розумінні.

Ефективним вирішенням такої проблеми $\epsilon$ застосування сурогатної оптимізації, що широко використовується в різноманітних галузях, наприклад в аерокосмічному будуванні, турбінобудуванні, будівництві, машино- та приладобудуванні тощо. Найбільшого поширення набули такі алгоритми побудови метамоделей: алгоритми поліноміального регресійного аналізу $[6,7]$, регресії на основі гаусівських процесів $[8,9]$, багатопараметричної нелінійної регресії, крігінг [10], адаптивні алгоритми регресійного аналізу $[11,12]$, еволюційні алгоритми самоорганізації [13], алгоритми штучних нейронних мереж [14].

Одним із недоліків алгоритму поліноміального регресійного аналізу $є$ проблема вибору порядку моделі залежно від складності функції цілі $[6,7]$. Реалізується ітеративно в бік підвищення. Для регресії на основі гаусівських процесів необхідно мати в наявності заздалегідь задану коваріаційну функцію, яка необхідна при оцінюванні параметрів цих процесів, що відповідно впливає на обчислювальну складність методу [8, 9]. Розрахунок параметрів метамоделі методом максимальної правдоподібності виконується в крігінговому методі [10]. При цьому розрахунок виходу моделі крігінговим методом передбачає виконання досить громіздких матричних перетворень, що суттєво впливає на складність реалізації зі збільшенням розмірності задачі.

В адаптивному алгоритмі регресійного аналізу розрахунок невідомих коефіцієнтів виконується методом найменших квадратів $[11,12]$. Так само, як і в попередньому алгоритмі, основним недоліком цього алгоритму $\epsilon$ складнощі розрахунку коефіцієнтів моделі, коли розв'язується задача великої розмірності. Вибір оптимальної структури моделі передбачає і метод МГУА, де здійснюється сортування поступово ускладнених моделей [13]. Метод потребує додаткових інтелектуальних зусиль на пошук ефективного виду моделі. Завдяки тому, що RBF-нейронна мережа має лише один прихований шар нейронів, а це суттєво спрощує задачу вибору архітектури мережі, ці мережі мають широке застосування при побудові метамоделей у різноманітних технічних задачах [14]. Окрім того, такі мережі швидко навчаються, оскільки використовують добре вивчені методи лінійної оптимізації при підборі параметрів лінійної комбінації у вихідному шарі мережі. Зважуючи на переваги та недоліки відомих апроксимаційних методів, у цьому дослідженні використано математичний апарат штучних нейронних мереж.

Задачу оптимального синтезу НВСП в загальному випадку вирішують у декілька етапів: 1-й етап - побудова метамоделі з використання RBF-мережі з гаусовою функцією активації; 2-й етап - оптимальний синтез; 3-й етап - перевірка на «точних» електродинамічних моделях отриманого результату та корекція структури збудження НВСП (рисунок 1).

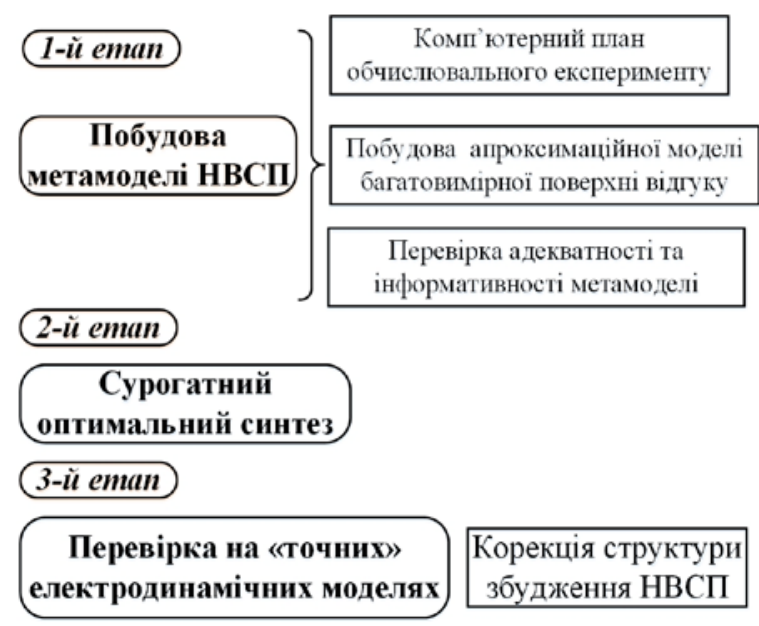

Рисунок 1 - Етапи виконання оптимального синтезу НВСП

Мета роботи: побудова RBFметамоделі кругового вихрострумового перетворювача та оцінювання іiі точності із перевіркою метамоделі на адекватність, інформативність та достовірність. 
Виклад основного матеріалу дослідження. Розглянемо модельний приклад побудови метамоделі нерухомого НВСП у вигляді витка, що розташований над ОК, при таких вихідних даних: товщина струмопровідного матеріалу ОК $d=10$ мм; висота розташування над OK $z_{0}=3$ мм; частота струму збудження $f=1$ кГц; електрофізичні параметри матеріалу $\sigma=3,745 \cdot 10^{7} \mathrm{Cm} / \mathrm{M}, \mu_{\mathrm{r}}=1$.

В подальшому побудова метамоделі ВСП розглядається як рішення кожної окремої підзадачі (рисунок 1). Початковим для побудови метамоделі є створення плану експерименту із рівномірним комп'ютерним заповненням точками багатовимірного простору пошуку. Кількість точок дорівнює $\mathrm{N}_{\text {вітдв. }}$ Враховуючи переваги та недоліки різноманітних генераторів розподілу точок [15], в дослідженні використано сукупності ЛП т-послідовностей Соболя $\xi_{1}, \xi_{2}, \ldots, \xi_{52}$. Так, наприклад, для підобласті $2 \leq r \leq 6$ мм реалізовувалися такі випадки ЛП $\xi_{1}, \xi_{3}, \xi_{5}$, а для $6<r \leq 11$ мм - послідовності $\xi_{1}, \xi_{2}, \xi_{6}$.

Побудову метамоделі виконано при варіюванні трьох параметрів у межах $x=0 . .30$ мм; $y=0 \ldots 30$ мм; $r=2 . .15$ мм та за умови, що НВСП нерухомий, тобто $\vec{v}=(0,0,0)$. Метамоделі, отримані за допомогою одинарних RBF нейронних мереж, показали низьку точність [1]. Тому доцільним $\epsilon$ застосування додаткових методів підвищення точності нейромережевого рішення [16]. Так, у роботі [1] побудовано множинну RBFметамодель, яка має вигляд комітету нейронних мереж. При такій побудові вдалося лише незначно зменшити величину середньої модельної похибки апроксимації МАРЕ, \%. Зокрема, одинарні RBF-мережі на етапі навчання мають МАРЕ від $22 \%$ до $29 \%$, тоді як мережі, організовані в комітет, забезпечують МАРЕ на етапі навчання до 18,08 \% та на етапі відтворення - до $19,8 \%$, тобто похибка зменшується лише на 4-9 \%, що недостатньо для відтворення поверхні відгуку. При побудові мережі у вигляді композита із одиночних мереж [16] вдається досягти зменшення МАРЕ майже в два рази на обох етапах побудови. Зокрема, композитна мережа iз восьми каскадів дає МАРЕ до 10,12\% при навчанні та 15,93 \% при відтворенні поверхні відгуку. Таким чином, доцільно застосувати при побудові метамоделі архітектуру гібридної множинної мережі, що складається із композитів та комітетів нейронних мереж.

Для підвищення точності побудови метамоделі область пошуку розділено на три підобласті: $\quad 2 \leq r \leq 6$ мм, $\quad 6<r \leq 11$ мм, $11<r \leq 15$ мм, для яких отримано апроксимаційні залежності 3 використанням гібридної множинної мережі, тобто застосовується декомпозиція.

Створено групи RBF-нейронних мереж для кожної із підобластей із кількістю точок плану експерименту $N_{\text {навч }} \in N_{\text {відтв }}$, яких відібрано найкращі (таблиці 1-3). Для оцінювання якості отриманої метамоделі на етапі навчання використано чисельні показники коефіцієнта детермінації $R^{2}$, відношення стандартних відхилень S.D.ratio; середньої відносної величини модельної похибки (або середньої похибки апроксимації) MAPE, \%, суми квадратів залишків $S S_{R}$, середнього квадрата залишків $M S_{R}$. Також проводиться графічний аналіз залишків у вигляді гістограми та діаграми розсіювання значень модуля ГВС для «точної» моделі $J_{i k}$ та побудованої метамоделі $\hat{J}_{i k}$. Надалі перевіряється правильність відтворюваності поверхні відгуку за допомогою отриманої математичної моделі в усій області моделювання. Оцінювання відновлення поверхні відгуку виконується за допомогою формули, що описує вихід RBF-мережі [1].

В таблицях 1-3 наведено архітектуру кожного каскаду композитної мережі та мережі, які використовувалися для створення комітетів для відповідних підобластей пошуку, а також чисельні показники якості множинної нейронної мережі при навчанні та відтворенні.

Для порівняння ефективності метамоделі $J_{1}$ на першому та $J_{\sum \text { комітет }}$ на останньому каскаді мереж для відповідних підобластей на рисунках 3, 4, 8, 9, 13, 14 наведено результати чисельного моделювання відновлення поверхні відгуку, що відтворена на точках вибірки $N_{\text {вiдm. }}$. Для прикладу, результати подано у вигляді ліній рівня відновленої поверхні відгуку для радіусів $r=5,10,15$ мм і діаграми розсіювання значень «точної» та відновленої функції.

На рисунках $5, a, 6, \sigma, 10, a, 11, \sigma, 15, a$, $16, \sigma$ зображено результати відносної модельної похибки апроксимації поверхні відгуку, що представлено у вигляді ліній рівня та гіс- 


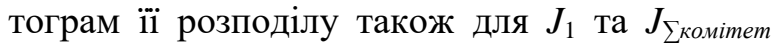
кожної підобласті відповідно.

На рисунках 2, $a, 7, a, 12, a$ зображено деякі статистичні показники, отримані за допомогою універсальної комп'ютерноінтегрованої системи STATISTICA. Використовуючи їх, оцінено адекватність та достовір- ність отриманих метамоделей для зазначених підобластей. За допомогою модуля Correlation matrices отримано значення коефіцієнта кореляції та коефіцієнта детермінаціiі. 3 їх використанням оцінюється інформативність метамоделей для кожної підобласті (рисунки 2, б, 7, б, 12, б).

Таблиця 1 - Чисельні показники якості множинної нейронної мережі для підобласті $2 \leq r \leq 6$ мм

\begin{tabular}{|c|c|c|c|c|c|c|c|}
\hline \multirow{2}{*}{$\begin{array}{l}\text { Композитна } \\
\text { нейромережа }\end{array}$} & \multirow{2}{*}{$\begin{array}{c}\text { Метамоделі, що } \\
\text { є складовими } \\
\text { композита }\end{array}$} & \multicolumn{2}{|c|}{ MAPE,\% } & \multicolumn{2}{|c|}{$M S_{R}$} & \multicolumn{2}{|c|}{$S S_{R}$} \\
\hline & & $\begin{array}{c}\text { нав- } \\
\text { чання } \\
N=1036\end{array}$ & $\begin{array}{c}\text { відтво- } \\
\text { рення } \\
N=2060\end{array}$ & $\begin{array}{c}\text { нав- } \\
\text { чання }\end{array}$ & $\begin{array}{l}\text { відтво- } \\
\text { рення }\end{array}$ & $\begin{array}{l}\text { нав- } \\
\text { чання }\end{array}$ & $\begin{array}{c}\text { відтво- } \\
\text { рення }\end{array}$ \\
\hline$J_{1}$ & RBF-3-299-1(1) & 11.49 & 12.9 & 0.000437 & 0.000691 & 0.453 & 1.425 \\
\hline$J_{2}$ & RBF-3-302-1(5) & 9,91 & 11,07 & 0,000103 & 0,000332 & 0,107 & 0,685 \\
\hline$J_{3}$ & RBF-3-300-1(30) & 7,88 & 9,27 & 0,0000731 & 0,000374 & 0,0758 & 0,772 \\
\hline$J_{4}$ & RBF-3-305-1(46) & 6,51 & 7,97 & 0,0000596 & 0,000314 & 0,0618 & 0,647 \\
\hline \multirow{4}{*}{$J_{5}$} & RBF-3-297-1(4) & 6,05 & 7.45 & 0,0000480 & 0,000317 & 0,0498 & 0,654 \\
\hline & RBF-3-298-1(9) & 6,15 & 7,43 & 0,0000381 & 0,000280 & 0,0395 & 0,578 \\
\hline & RBF-3-299-1(12) & 5,98 & 7,39 & 0,0000444 & 0,000299 & 0,046 & 0,617 \\
\hline & RBF-3-306-1(48) & 5,98 & 7,32 & 0,0000415 & 0,000283 & 0,043 & 0,584 \\
\hline$J_{\text {¿комітет }}$ & $\begin{array}{l}\text { №4+№9+№12+ } \\
\text { +№48 }\end{array}$ & 5,38 & 6,76 & 0,000038 & 0,000289 & 0,0394 & 0,597 \\
\hline
\end{tabular}

\begin{tabular}{|c|c|c|c|c|c|c|c|c|}
\hline \multicolumn{8}{|c|}{ Working_error_2_5 $\mathrm{Mm}^{*}$ - Descriptive statistics (Table_x_y_r0_r_2_5) } & \multirow[t]{2}{*}{$\square \square$} \\
\hline \multirow{2}{*}{ 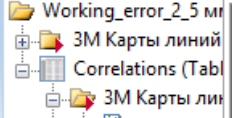 } & \multirow[b]{2}{*}{ Переменная } & \multicolumn{6}{|c|}{ Descriptive statistics (Table_x_y_r0_r_2_5) } & \\
\hline & & N набл. & Среднее & Сумма & Минимум & Максим. & Дисперсия & Ст.откп. \\
\hline Карты лин & Jplan_norm & 2060 & 0,083896 & 172,8260 & 0,000000 & 1,000000 & 0,023062 & 0,151862 \\
\hline 臤 Гистограм & $\mathrm{J} 1+\mathrm{J} 2+\mathrm{J} 3+\mathrm{J} 4+\mathrm{J} 5$ & 2060 & 0,083215 & 171,4231 & $-0,018909$ & 0,967497 & 0,022764 & 0,150879 \\
\hline 啊 Карты лин & J5_остатки & 2060 & 0,000677 & 1,3952 & $-0,467543$ & 0,179869 & 0,000290 & 0,017027 \\
\hline Картылин & J5_остатки - Абс. Ост. & 2060 & 0,004231 & 8.7152 & 0,000002 & 0,467543 & 0,000272 & 0,016507 \\
\hline Диаграмм & SSR & 2060 & 0,000290 & 0.5979 & 0,000000 & 0,218596 & 0,000026 & 0,005128 \\
\hline Descriptive sta & SSD & 2060 & 0,022754 & 46,8729 & 0,000000 & 0,780751 & 0,007024 & 0,083809 \\
\hline & SST & 2060 & 0,023051 & 47,4851 & 0,000000 & 0,839246 & 0,007257 & 0,085187 \\
\hline
\end{tabular}

a)

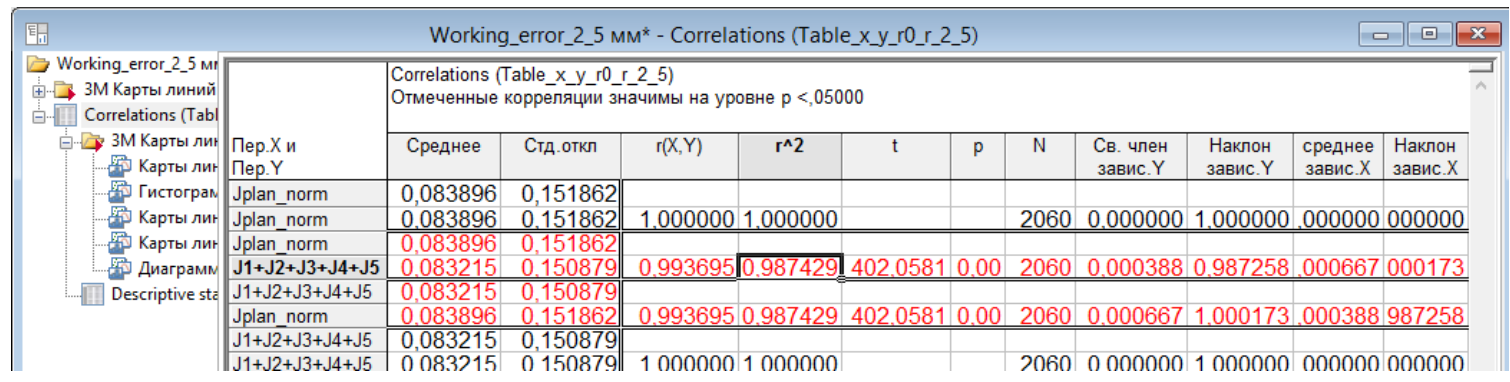

б)

Рисунок 2 - Статистичні показники

для оцінювання адекватності та інформативності метамоделі для підобласті $2 \leq r \leq 6$ мм 


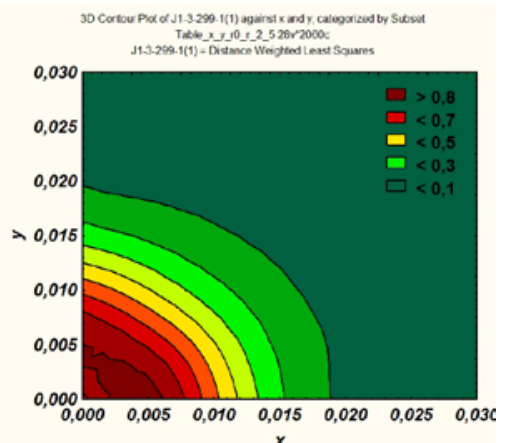

a)

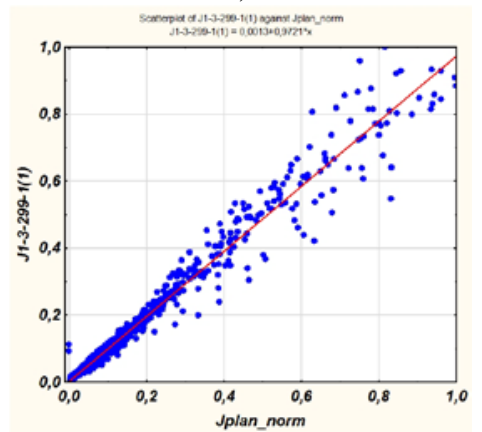

б)

a) лінії рівня відновленої поверхні відгуку для радіуса $r=5$ мм; б) діаграми розсіювання значень «точної» та відновленої функції

Рисунок 3 - Відтворення поверхні відгуку за допомогою метамоделі RBF-3-299-1(1)

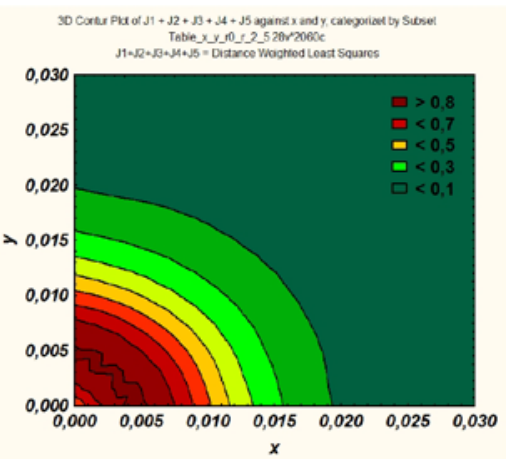

a)

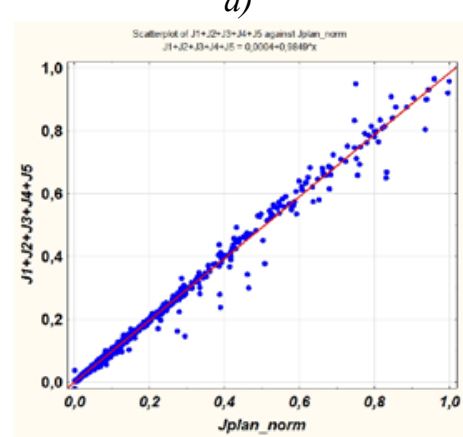

б)

a) лінії рівня відновленої поверхні відгуку для радіуса $r=5$ мм; б) діаграми розсіювання значень «точної» та відновленої функції

Рисунок 4 - Відтворення поверхні відгуку за допомогою метамоделі $\boldsymbol{J}_{\text {¿комітет }}$

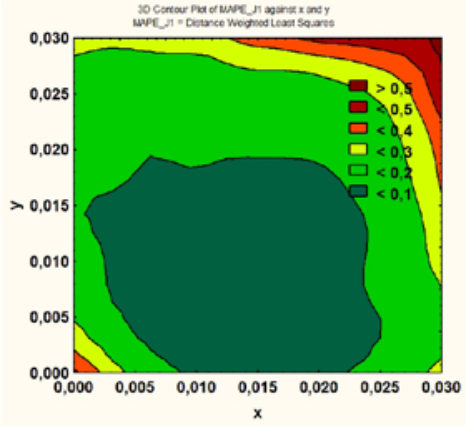

a)

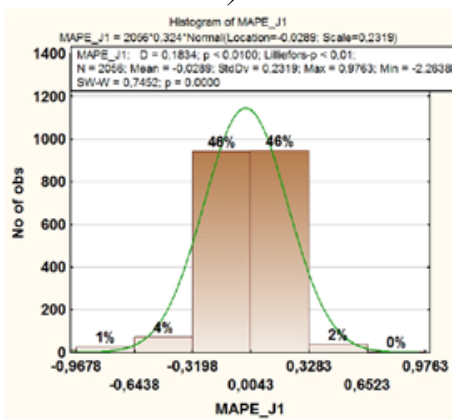

б)

a) лінії рівня для підобласті $2 \leq r \leq 6$ мм;

б) гістограми розподілу цієї похибки

Рисунок 5 - Відносна модельна похибка апроксимації поверхні відгуку для метамоделі RBF-3-299-1(1)

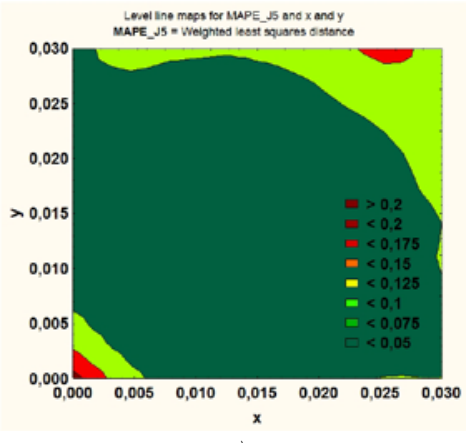

a)

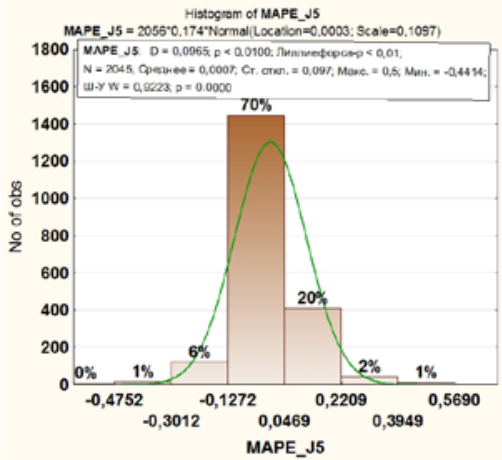

б)

a) лінії рівня для підобласті $2 \leq r \leq 6$ мм;

б) гістограми розподілу цієї похибки

Рисунок 6 - Відносна модельна похибка апроксимації поверхні відгуку для метамоделі $\boldsymbol{J}_{\text {¿комімет }}$

(C) Р. В. Трембовецька, В. Я. Гальченко, В. В. Тичков, А. В. Сторчак, 2019 DOI: 10.24025/2306-4412.2.2019.171272 
Для перевірки відповідності отриманої функції відгуку експериментальним даним встановлювалась адекватність отриманої математичної моделі за критерієм Фішера:

$$
F_{n_{D} ; n_{R}}^{\text {ексn }}>F_{a ; n_{D} ; n_{R}}^{\text {криum }}, F_{n_{D} ; n_{R}}^{\text {eксn }}=\frac{M S_{D}}{M S_{R}},
$$

де $F_{\alpha ; v_{D} ; v_{R}}^{\text {крит }}$ - критичне значення критерію Фішера, заздалегідь розраховане значення з певним рівнем значущості $\alpha$; $M S_{D}=\frac{S S_{D}}{n_{D}}-$ середній квадрат регресії; $M S_{R}=\frac{S S_{R}}{N-n-1}-$ середній квадрат залишків; $S S_{D}$ - сума квадратів регреciї; $S S_{R}$ - сума квадратів залишків; $S S_{T}$ загальна сума квадратів; $v_{D}=n, v_{R}=N-n-1-$ кількість степенів свободи, $N$ - кількість спостережень; $n$ - кількість заданих незалежних змінних.

Тоді отримана метамодель $J_{\text {Гансамбль }}$ для підобласті $2 \leq r \leq 6$ мм має експериментальне значення показника Фішера $F_{v_{D} ; v_{R}}^{\text {eксn }}=F_{3 ; 2056}^{\text {eксn }}=78,886$, а критичне значення цього критерію з рівнем значущості $\alpha=5$ \% i кількістю степенів свободи $v_{R}=2056, v_{D}=3$ становить $F_{\alpha ; \nu_{D} ; v_{R}}^{\text {kpum }}=F_{0,05 ; 3 ; 2056}^{\text {kpum }}=2,6$. Таким чином, умова (1) виконується, метамодель адекватна і прогноз результатів по моделі не суперечить дійсності.

Перевірка моделі на інформативність проводиться шляхом розрахунку коефіцієнта детермінації $R^{2}$ :

$$
R^{2}=\frac{S S_{D}}{S S_{T}}=\frac{S S_{T}-S S_{R}}{S S_{T}}=1-\frac{S S_{R}}{S S_{T}} .
$$

Перевірку гіпотези про значущість множинного коефіцієнта кореляції $R^{2}$ (інформативність моделі) виконано з використанням F-критерію Фішера (1), де

$$
F_{v_{D} ; v_{R}}^{\text {ekcn }}=\frac{R^{2}}{1-R} \cdot \frac{v_{R}}{v_{D}} .
$$

Метамодель інформативна, оскільки $R^{2}>0,95$ (рисунок 2, б), та значимо достовірна за F-критерієм при рівні значущості $5 \%$, оскільки умова (1) виконується для експериментального значення $F_{3 ; 2056}^{\text {ексn }}=75,812$.

\begin{tabular}{|c|c|c|c|c|c|c|c|}
\hline \multirow{2}{*}{$\begin{array}{l}\text { Композитна } \\
\text { нейромережа }\end{array}$} & \multirow{2}{*}{$\begin{array}{c}\text { Метамоделі, що є } \\
\text { складовими } \\
\text { композита }\end{array}$} & \multicolumn{2}{|c|}{ MAPE,\% } & \multicolumn{2}{|c|}{$M S_{R}$} & \multicolumn{2}{|c|}{$S S_{R}$} \\
\hline & & $\begin{array}{c}\text { навчання } \\
N=1299\end{array}$ & \begin{tabular}{|c|} 
відтворення \\
$N=2575$
\end{tabular} & навчання & $\begin{array}{c}\text { відтво- } \\
\text { рення }\end{array}$ & навчання & $\begin{array}{l}\text { відтво- } \\
\text { рення }\end{array}$ \\
\hline$J_{1}$ & RBF-3-329-1(8) & 10.04 & 9.82 & 0.000361 & 0.000406 & 0.469 & 1.046 \\
\hline$J_{2}$ & RBF-3-332-1(1) & 6,36 & 6,52 & 0,000192 & 0,000246 & 0,250 & 0,636 \\
\hline$J_{3}$ & RBF-3-328-1(8) & 5,69 & 6,01 & 0,000127 & 0,000183 & 0,165 & 0,472 \\
\hline \multirow[t]{4}{*}{$J_{4}$} & RBF-3-326-1(3) & 5,07 & 5,38 & 0,000102 & 0,000159 & 0,133 & 0,411 \\
\hline & RBF-3-329-1(20) & 5,04 & 5,25 & 0,000101 & 0,000160 & 0,132 & 0,414 \\
\hline & RBF-3-326-1(42) & 4,99 & 5.49 & 0,000101 & 0,000163 & 0,132 & 0,422 \\
\hline & RBF-3-332-1(80) & 4,91 & 5,13 & 0,0001 & 0,000157 & 0,13 & 0,399 \\
\hline & №3+№20+o42++№80 & 4,48 & 4,8 & 0,0000894 & 0,000146 & 0,116 & 0,378 \\
\hline
\end{tabular}

Таблиця 2 - Чисельні показники якості множинної нейронної мережі для підобласті

\begin{tabular}{|c|c|c|c|c|c|c|c|c|c|}
\hline \multicolumn{9}{|c|}{ Working_error_r_6_10 - Descriptive statistics (Table_x_y_r0_r_6_10) } & \multirow[t]{2}{*}{$\square \square$} \\
\hline \multirow{2}{*}{ 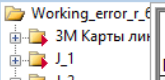 } & \multirow{2}{*}{ Переменная } & \multicolumn{7}{|c|}{ Descriptive statistics (Table $x$ y $r 0$ r 6 10) } & \\
\hline & & N набл. & Среднее & Сумма & Минимум & Максим. & Дисперсия & Ст. откл. & $\begin{array}{l}\text { Станд. } \\
\text { ошибки }\end{array}$ \\
\hline$\oplus \rightarrow J_{-}$ & Jplan_norm & & & & & & & & 0,004646 \\
\hline$\rightarrow-3$ & $J 1+J 2+J \_3+J$ & 2575 & 0, & 482,6222 & 0,0 & 1,0 & 00 & 0.2 & 0,004632 \\
\hline J_4 ансамбль & J 4 oct & & & 1.8413 & & & & & \\
\hline 由. Таблица г & $\overline{S S R}$ & 2575 & & 0.3783 & 0.0 & 0,0 & & & 0,000018 \\
\hline Таблица г & SST & & & $\frac{0.5}{143}$ & & & & & 0,002 \\
\hline (1) Таблица г & SSD & 2575 & 0,055227 & 142,2107 & 0,000000 & 0,695184 & 0,012646 & 0,112455 & 0,002216 \\
\hline
\end{tabular}
$\mathbf{6}<\boldsymbol{r} \leq \mathbf{1 1}$ мм

a)

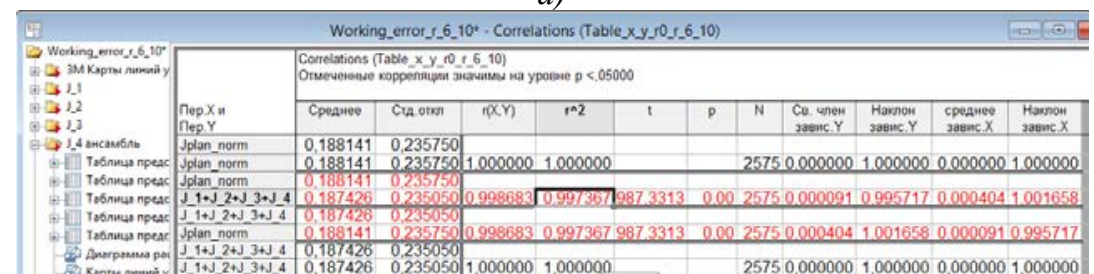

б)

Рисунок 7 - Статистичні показники для оцінювання адекватності та інформативності метамоделі для підобласті $6<\boldsymbol{r} \leq \mathbf{1 1}$ мм

(c) Р. В. Трембовецька, В. Я. Гальченко, В. В. Тичков, А. В. Сторчак, 2019 DOI: 10.24025/2306-4412.2.2019.171272 

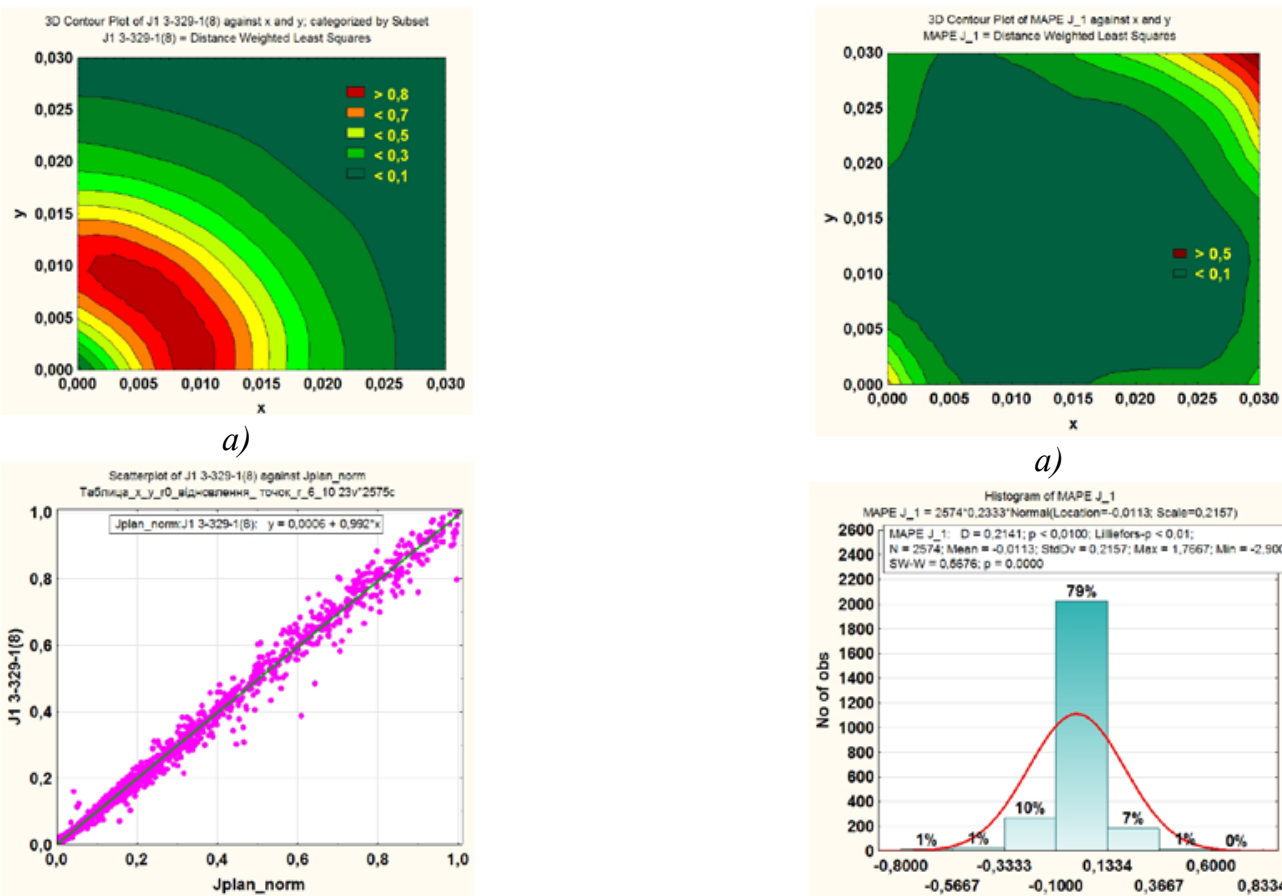

a)

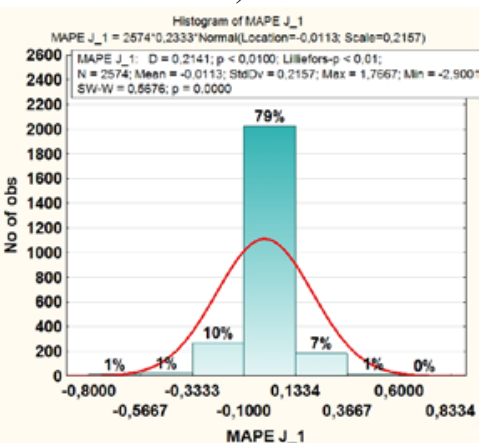

б)

a) лінії рівня відновленої поверхні відгуку для радіуса $r=10$ мм; б) діаграми розсіювання значень «точної» та відновленої функції

Рисунок 8 - Відтворення поверхні відгуку за допомогою метамоделі RBF-3-329-1(8)
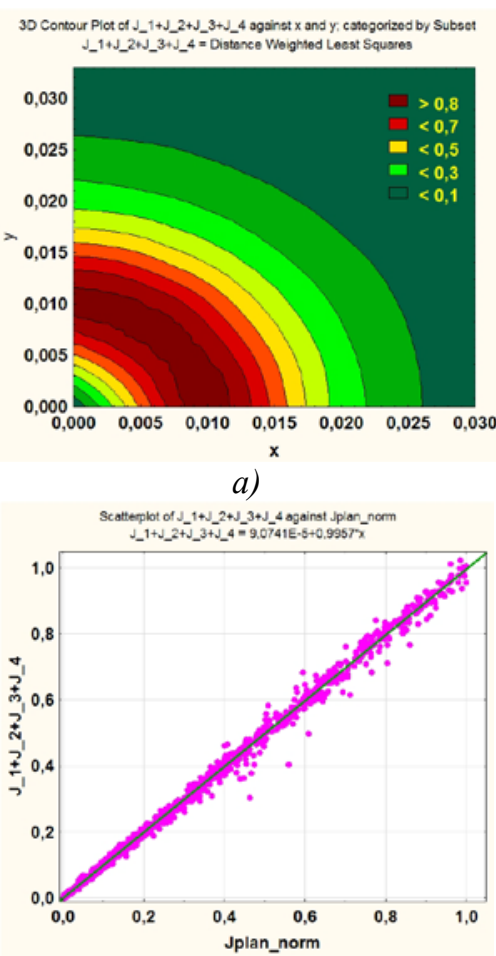

б)

a) лінії рівня відновленої поверхні відгуку для радіуса $r=10$ мм; б) діаграми розсіювання значень «точної» та відновленої функції

Рисунок 9 - Відтворення поверхні відгуку за допомогою метамоделі $\boldsymbol{J}_{\text {¿комімет }}$

a) лінії рівня для підобласті $6<r \leq 11$ мм;

б) гістограми розподілу цієї похибки

Рисунок 10 - Відносна модельна похибка апроксимації поверхні відгуку для метамоделі RBF-3-329-1(8)

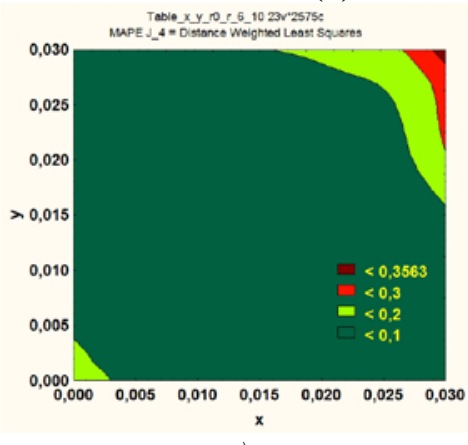

a)

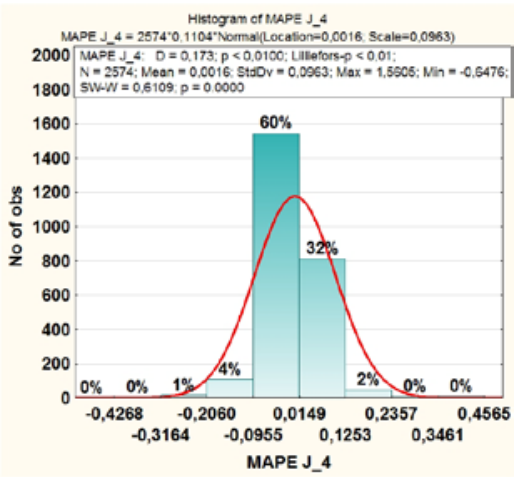

б)

a) лінії рівня для підобласті $6<r \leq 11$ мм; б) гістограми розподілу цієї похибки

Рисунок 11 - Відносна модельна похибка апроксимації поверхні відгуку для метамоделі $\boldsymbol{J}_{\text {Екомітет }}$

(C) Р. В. Трембовецька, В. Я. Гальченко, В. В. Тичков, А. В. Сторчак, 2019 DOI: $10.24025 / 2306-4412.2 .2019 .171272$ 
Для підобласті $6<r \leq 11$ мм експериментальне значення показника Фішера становить $F_{v_{D} ; v_{R}}^{\text {ексn }}=F_{3 ; 2571}^{\text {ексn }}=375$, а критичне значення Фішера 3 рівнем значущості $\alpha=5 \%$ і кількістю степенів свободи $v_{R}=2571, v_{D}=3$ дорівнює крит

$F_{0,05 ; 3 ; 2571}^{\text {крит }}=2,6$. Умова (1) виконується, метамодель для цієї підобласті є адекватною.
Експериментальне значення $F$-критерію Фішера для перевірки гіпотези про значущість множинного коефіцієнта кореляції становить $F_{3 ; 2571}^{\text {ексn }}=331,91$. Отже, метамодель

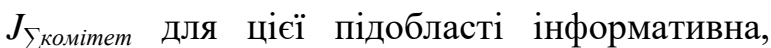
оскільки $R^{2}>0,95$ (рисунок 7,6 ), та значимо достовірна за $F$-критерієм Фішера при $\alpha=5 \%$.

Таблиця 3 - Чисельні показники якості композитної нейронної мережі для підобласті $11<r \leq 15$ мм

\begin{tabular}{|c|c|c|c|c|c|c|c|}
\hline \multirow{2}{*}{$\begin{array}{c}\text { Композитна } \\
\text { нейро- } \\
\text { мережа }\end{array}$} & \multirow{2}{*}{$\begin{array}{c}\text { Метамоделі, що } \\
\text { є складовими } \\
\text { композита }\end{array}$} & \multicolumn{2}{|c|}{ MAPE,\% } & \multicolumn{2}{|c|}{$M S_{R}$} & \multicolumn{2}{|c|}{$S S_{R}$} \\
\hline & & $\begin{array}{c}\text { навчання } \\
N=1040\end{array}$ & $\begin{array}{c}\text { відтворення } \\
N=2061\end{array}$ & $\begin{array}{l}\text { нав- } \\
\text { чання }\end{array}$ & $\begin{array}{l}\text { відтво- } \\
\text { рення }\end{array}$ & $\begin{array}{l}\text { нав- } \\
\text { чання }\end{array}$ & $\begin{array}{c}\text { відтво- } \\
\text { рення }\end{array}$ \\
\hline$J_{1}$ & RBF-3-297-1(2) & 7,94 & 7,77 & 0,000698 & 0,000883 & 0,725 & 1,821 \\
\hline$J_{2}$ & RBF-3-300-1(11) & 5,75 & 6,55 & 0,000365 & 0,000619 & 0,38 & 1,276 \\
\hline$J_{3}$ & RBF-3-300-1(13) & 4,7 & 5,68 & 0,000245 & 0,000503 & 0,252 & 1,038 \\
\hline$J_{4}$ & RBF-3-306-1(77) & 4,11 & 5,12 & 0,000181 & 0,000428 & 0,189 & 0,883 \\
\hline \multirow[t]{3}{*}{$J_{5}$} & RBF-3-297-1(1) & 3,74 & 5,04 & 0,000149 & 0,000396 & 0,155 & 0,817 \\
\hline & RBF-3-301-1(22) & 3,72 & 4,8 & 0,000142 & 0,000380 & 0,148 & 0,785 \\
\hline & RBF-3-309-1(63) & 3,79 & 4.94 & 0,000149 & 0,000392 & 0,155 & 0,808 \\
\hline$\overline{J_{\Gamma_{\text {коми }}}}$ & №1+o22++№63 & 3,56 & 4,78 & 0,000136 & 0,000379 & 0,142 & 0,782 \\
\hline
\end{tabular}

\begin{tabular}{|c|c|c|c|c|c|c|c|c|}
\hline \multicolumn{2}{|l|}{ 聇 } & \multicolumn{7}{|c|}{ Working_error_r_11_15 - Descriptive statistics (Table_x_y_r0_r_11_15) } \\
\hline \multirow{2}{*}{ 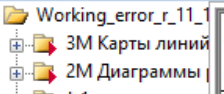 } & \multirow[b]{2}{*}{ Переменная } & \multicolumn{7}{|c|}{ Descriptive statistics (Table_x_y_r0_r 11_15) } \\
\hline & & N набл. & Среднее & Сумма & Минимум & Максим. & Дисперсия & Ст.откл. \\
\hline$\oplus \longrightarrow$ J_1 & Jplan_norm & 2060 & 0,307579 & 633,6120 & 0,000000 & 1,000000 & 0,079280 & 0,281568 \\
\hline$\stackrel{\leftrightarrow}{\rightarrow} J_{-} 2$ & $\mathrm{~J}\left(1+\mathrm{J} \_2+\mathrm{J}-3+\mathrm{J} \_4+\mathrm{J}-5\right.$ & 2060 & 0,305711 & 629,7639 & 0,012394 & 1,061280 & 0,078701 & 0,280537 \\
\hline 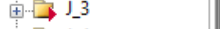 & J_5 остатки & 2060 & 0,001868 & 3.8481 & $-0,106473$ & 0,370844 & 0,000376 & 0,019404 \\
\hline$\oplus \rightarrow$ & SSR & 2060 & 0,000380 & 0,7824 & 0,000000 & 0,137525 & 0,000013 & 0,003545 \\
\hline 当 J_5 & SST & 2060 & 0,079242 & $\overline{163}, 0,7824$ & 0,000000 & 0,479627 & 0,011183 & 0,105748 \\
\hline$\boxminus$ ансамбль_1+ & SSD & 2060 & 0,078666 & 162,0520 & 0,000000 & 0,568261 & 0,010675 & 0,103319 \\
\hline
\end{tabular}

a)

\begin{tabular}{|c|c|c|c|c|c|c|c|c|c|c|c|c|}
\hline \multicolumn{2}{|l|}{ 目 } & \multicolumn{6}{|c|}{ Working_error_r_11_15* - Correlations (Table_x_y_ro_r_11_15) } & & & & & 口 回E \\
\hline $\begin{array}{l}{[\text { Working_error____11__ }} \\
\longrightarrow 3 \text { Карты линий } \\
\longrightarrow 2 \mathrm{M} \text { Диаграммы I }\end{array}$ & & \begin{tabular}{|l|} 
Correlations (T \\
Отмеченные \\
(Построчное )
\end{tabular} & $\begin{array}{l}\text { Table_x_y_r0 } \\
\text { корреляции } \\
\text { удаление ПД }\end{array}$ & $\begin{array}{l}\text { ___11_15) } \\
\text { значимы на ур } \\
\text { 1) }\end{array}$ & $e p$ & & & & & & & \\
\hline $\begin{array}{ll}J_{-} 1 \\
J_{-} 2\end{array}$ & $\begin{array}{l}\text { Пер.X } и \\
\text { Пер.Y }\end{array}$ & Среднее & Стд.откп & $r(X, Y)$ & $r^{\wedge} 2$ & $\mathrm{t}$ & $\mathrm{p}$ & $\mathrm{N}$ & $\begin{array}{l}\text { Св. член } \\
\text { завис.Ү }\end{array}$ & $\begin{array}{l}\text { Наклон } \\
\text { завис.Y }\end{array}$ & $\begin{array}{l}e e \\
x \\
x\end{array}$ & $\begin{array}{l}\text { Наклон } \\
\text { завис.X }\end{array}$ \\
\hline$\rightarrow J_{-} 3$ & 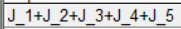 & 0,3 & 0,2 & & & & & & & & & \\
\hline$\theta J_{-} 4$ & 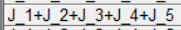 & 0.305711 & 0.280537 & 1.000000 & 1.000000 & & & 2060 & 0.000000 & 1.000000 & 0.000000 & 1.000000 \\
\hline 1.5 ансамбль $1+$ & $\begin{array}{l}\int \mathrm{J} 1+\mathrm{J} 2+\mathrm{J} 3+\mathrm{J} 4+\mathrm{J} 5 \\
\text { Jplan_norm }\end{array}$ & $\begin{array}{l}0.305711 \\
0.307579 \\
\end{array}$ & \begin{tabular}{|l|}
0.280537 \\
0.281568 \\
\end{tabular} & $0.997624 \Gamma$ & 0.995253 & 656.8518 & 0.00 & 2060 & 0.001474 & 1.001288 & -0.000014 & 0.993973 \\
\hline T1 таблица ! & $\begin{array}{l}\text { Jplan_norm } \\
\mathrm{J} 1+\mathrm{J} 2+\mathrm{J} 3+\mathrm{J} 4+\mathrm{J} 5\end{array}$ & $\begin{array}{l}0,307579 \\
0,305711\end{array}$ & \begin{tabular}{|l|}
0,281568 \\
0,280537
\end{tabular} & 0.997624 & 0.995253 & 656.8518 & 0.00 & 2060 & -0.000014 & 0.993973 & 0.00147 & 001288 \\
\hline Tаблица ' & $\begin{array}{l}\text { Jplan_norm } \\
\text { Jplan_norm }\end{array}$ & $\begin{array}{l}0,307579 \\
0,307579\end{array}$ & \begin{tabular}{|l|}
0,281568 \\
0,281568
\end{tabular} & 1,000000 & 1,000000 & & & 2060 & 0,000000 & 1,000000 & 0,000000 & 1,000000 \\
\hline
\end{tabular}

б)

Рисунок 12 - Статистичні показники для оцінювання адекватності та інформативності метамоделі для підобласті $11<r \leq 15$ мм

Для цього піддіапазону отримано експериментальне значення критерію Фішера $F_{v_{D} ; v_{R}}^{\text {eксn }}=F_{3 ; 2057}^{\text {ексn }}=207$. Як і для попередніх випадків, табличне значення критерію Фішера становить $F_{0,05 ; 3 ; 2057}^{\text {крит }}=2,6$. Отримана метамодель також адекватна за умовою (1).
Експериментальне значення $F$-критерію Фішера для перевірки гіпотези про значущість $R^{2}$ становить $F_{3 ; 2057}^{\text {ексn }}=198,6$. У результаті отримана метамодель для підобласті $11<r \leq 15$ мм інформативна, оскільки $R^{2}=0,995$ (рисунок $\left.12, \sigma\right)$, та значимо достовірна за $F$-критерієм Фішера при $\alpha=5 \%$. 


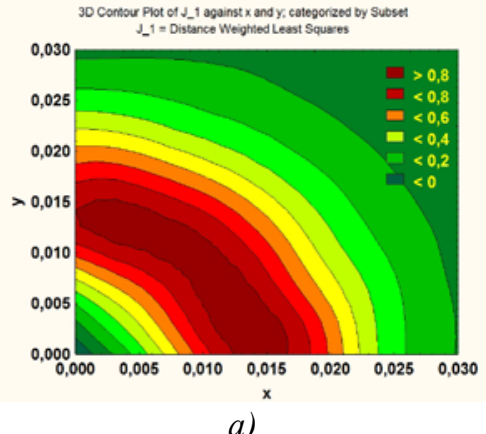

a)

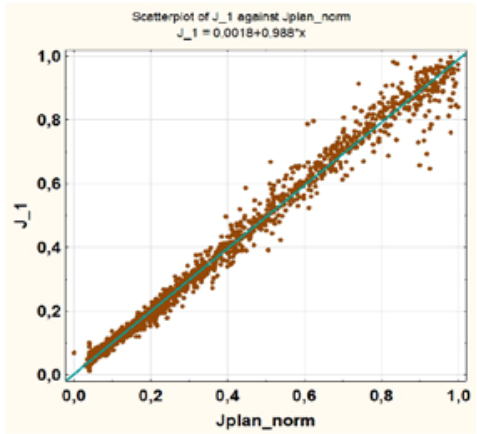

б)

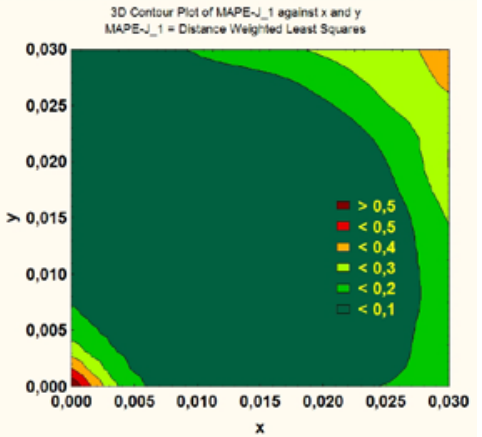

a)

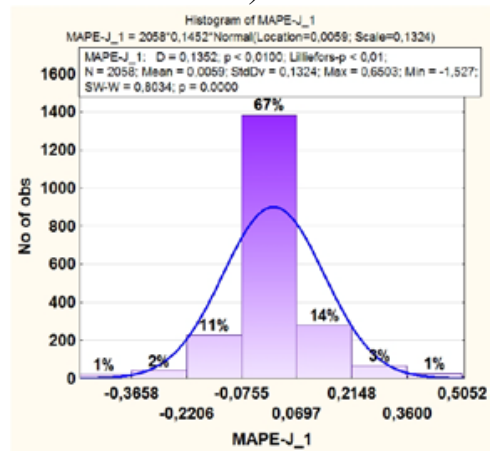

б)

a) лінії рівня відновленої поверхні відгуку для радіуса $r=15$ мм; б) діаграми розсіювання значень «точної» та відновленої функції

Рисунок 13 - Відтворення поверхні відгуку за допомогою метамоделі RBF-3-297-1(2)

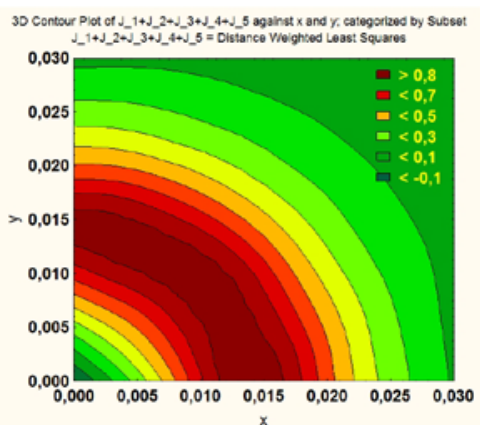

a)

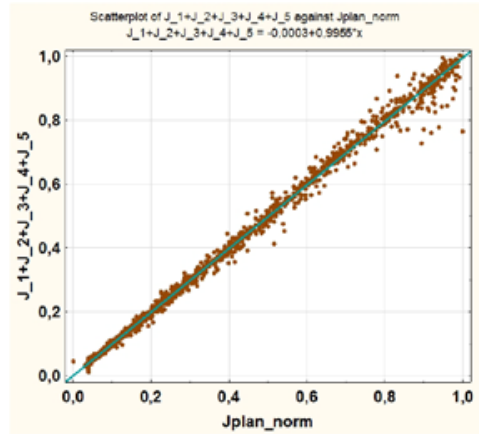

б)

a) лінії рівня відновленої поверхні відгуку для радіуса $r=15$ мм; б) діаграми розсіювання значень «точної» та відновленої функції

Рисунок 14 - Відтворення поверхні відгуку за допомогою метамоделі $\boldsymbol{J}_{\text {¿комітет }}$

a) лінії рівня для підобласті $11<r \leq 15$ мм; б) гістограми розподілу цісї похибки

Рисунок 15 - Відносна модельна похибка апроксимації поверхні відгуку для метамоделі RBF-3-297-1(2)

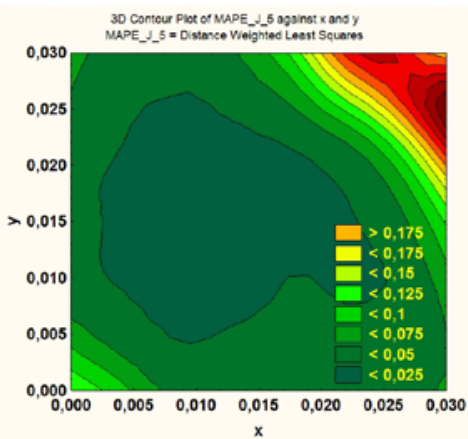

a)

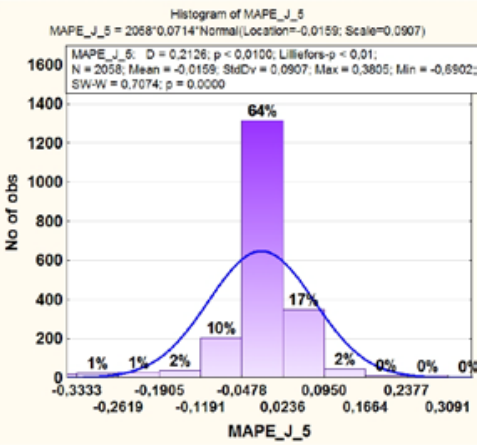

б)

a) лінії рівня для підобласті $11<r \leq 15$ мм;

б) гістограми розподілу цієї похибки

Рисунок 16 - Відносна модельна похибка апроксимації поверхні відгуку для метамоделі

$\boldsymbol{J}_{\text {乏комітет }}$

(C) Р. В. Трембовецька, В. Я. Гальченко, В. В. Тичков, А. В. Сторчак, 2019 DOI: $10.24025 / 2306-4412.2 .2019 .171272$ 
Висновки. Створено RBF-метамоделі концентричного кругового нерухомого НВСП. За рахунок побудови нейромережі у вигляді гібриду множинних мереж, що складається із композитів та комітету, зменшено значення МАРЕ. Отримані метамоделі мають середнє значення модельної похибки $6,76 \%$ для першої підобласті, 4,8 \% - для другої та $4,78 \%$ - для третьої. Отримані метамоделі адекватні за критерієм Фішера; інформативні за коефіцієнтом детермінації та значимо достовірні.

Таким чином створені метамоделі $\hat{J}_{i k}$ значно простіші в реалізації і менш ресурсоємні. Це дає можливість використовувати їх як одну зі складових цільової функції, а саме замість $J_{i k}$ в задачі оптимального синтезу НВСП.

\section{Список літератури}

[1] V. Ya. Halchenko, R. V. Trembovetska, and V. V. Tychkov, "Development of excitation structure RBF-metamodels of moving concentric eddy current probe", Electrical engineering \& electromechanics, № 2, pp. 2838, 2019.

[2] T. Itaya, K. Ishida, Ya. Kubota, A. Tanaka, and N. Takehira, "Visualization of eddy current distributions for arbitrarily shaped coils parallel to a moving conductor slab", Progress in Electromagnetics Research M., vol. 47, pp. 1-12, 2016.

[3] T. Itaya, K. Ishida, A. Tanaka, N. Takehira, and T. Miki, "Eddy current distribution for a rectangular coil arranged parallel to a moving conductor stab", IET Science, Measurement \& Technology, vol. 6, no. 2, pp. 43-51, 2012.

[4] K. Ishida, T. Itaya, A. Tanaka, and N. Takehira, "Magnetic field analysis of an arbitrary shaped coil using shape functions", IEEE Transactions on Magnetics, vol. 45, no. 1, pp. 104-112, 2009.

[5] R. V. Trembovetska, V. Ya. Halchenko, and V. V. Tychkov, "Studying the computational resource demands of mathematical models for moving surface eddy current probes for synthesis problems", Eastern-European Journal of Enterprise Technologies, vol. 95, no. 5/5, pp. 39-46, 2018.

[6] М. А. Чубань, "Аппроксимация поверхности отклика для использования в процессе параметрического синтеза машино- строительных конструкций", Вестник Наи. техн. ун-та "ХПИ": сб. науч. тр. Темат. вып.: Транспортное машиностроение. Харьков: НТУ "ХПИ", № 43 (1152), c. 161-164, 2015.

[7] С. Г. Радченко, "Анализ методов моделирования сложных систем", Математичні машини і системи, № 4, с. 123-127, 2015.

[8] Е. Бурнаев, М. Панов, Д. Кононенко, и И. Коноваленко "Сравнительный анализ процедур оптимизации на основе гауссовских процессов". [Электронный ресурс]. Режим доступа: http://itas2012.iitp.ru/pdf/1569602385.pdf. Дата обращения: Нояб. 4, 2015.

[9] Е. В. Бурнаев, П. Д. Ерофеев, и П.В.Приходько, "Выделение главных направлений в задаче аппроксимации на основе гауссовских процессов", Труды МФТИ, т. 5, №. 3, с. 24-35, 2013.

[10] N. V. Queipo, R. T. Haftka, W. Shyy, T. Goel, R. Vaidyanathan, and P. K. Tucker, "Surrogate-based analysis and optimization", Progress in Aerospace Sciences, vol. 41, no. 1, pp. 1-28, 2005.

[11] J. H. Frieman, "Multivariate adaptive regression splines", The Annals of Statistics, vol. 19, no. 1, pp. 1-67, 1991.

[12] В. Р. Целых, "Многомерные адаптивные регрессионные сплайны", Машинное обучение и анализ данных, т. 1, № 3, с. 272278, 2012.

[13] А. Г. Ивахненко, Индуктивный метод самоорганизачии моделей сложных систем. Киев: Наук. думка, 1982.

[14] П. В. Афонин, и О. Ю. Ламскова, "Алгоритмы оптимизации имитационных моделей сложных систем на основе нейронных сетей", Известия ЮФУ: Технические науки. Тематический выпуск "Интеллектуальные САПР», № 12 (101), с. 226-232, 2009.

[15] В. Я. Гальченко, Р.В. Трембовецька, та В. В. Тичков, "Застосування нейрокомп'ютинга на етапі побудови метамоделей в процесі оптимального сурогатного синтезу антен", Вісник НТУУ «КПI». Серія Радіотехніка. Радіоапаратобудування, № 74, с. 60-72, 2018.

[16] Р. В. Трембовецька, В. Я.Гальченко, та В. В. Тичков, "Методи покращення точності нейромережевих метамоделей накладних вихрострумових перетворювачів для сурогатного синтезу", в 2-nd Sci. 
Conf. with Internat. Participation NonDestructive Testing in Context of the Associated Membership of Ukraine in the European Union (NDT-UA 2018) (Poland, Lublin, 15-19 Oct. 2018), Poland: USNDT, 2018, No. 2, pp. 47-49.

\section{References}

[1] V. Ya. Halchenko, R. V. Trembovetska, and V. V. Tychkov, "Development of excitation structure RBF-metamodels of moving concentric eddy current probe", Electrical engineering \& electromechanics, no. 2, pp. 2838, 2019.

[2] T. Itaya, K. Ishida, Ya. Kubota, A. Tanaka, and N. Takehira, "Visualization of eddy current distributions for arbitrarily shaped coils parallel to a moving conductor slab", Progress in Electromagnetics Research M., vol. 47, pp. 1-12, 2016.

[3] T. Itaya, K. Ishida, A. Tanaka, N. Takehira, and T. Miki, "Eddy current distribution for a rectangular coil arranged parallel to a moving conductor stab", IET Science, Measurement \& Technology, vol. 6, no. 2, pp. 43-51, 2012.

[4] K. Ishida, T. Itaya, A. Tanaka, and N. Takehira, "Magnetic field analysis of an arbitrary shaped coil using shape functions", IEEE Transactions on Magnetics, vol. 45, no. 1, pp. 104-112, 2009.

[5] R. V. Trembovetska, V. Ya. Halchenko, and V. V. Tychkov, "Studying the computational resource demands of mathematical models for moving surface eddy current probes for synthesis problems", Eastern-European Journal of Enterprise Technologies, vol. 95, no. 5/5, pp. 39-46, 2018.

[6] M. A. Chuban, "Approximation of the response surface for the use in the process of parametric synthesis of engineering structures", Vestnik Nats. tehn. un-ta "HPI". Themat. issue: Transport machine-building: coll. of sci. papers. Kharkov: NTU "HPI", no. 43 (1152), pp. 161-164, 2015 [in Russian].

[7] S. G. Radchenko, "Analysis of methods for modeling complex systems", Matematychni mashyny i systemy, no. 4, pp. 123-127, 2015 [in Russian].
[8] E. Burnaev, M. Panov, D. Kononenko, and I. Konovalenko, "Comparative analysis of optimization procedures based on Gaussian processes". [Online]. Available: http://itas2012.iitp.ru/pdf/1569602385.pdf. Accessed on: Nov. 4, 2015.

[9] E. V. Burnaev, P. D. Erofeev, and P. V. Prikhodko, "Highlighting of the main directions in the approximation problem based on Gaussian processes", Trudyi MFTI, vol. 5, no. 3, pp. 24-35, 2013 [in Russian].

[10] N. V. Queipo, R. T. Haftka, W. Shyy, T. Goel, R. Vaidyanathan, and P. K. Tucker, "Surrogate-based analysis and optimization", Progress in Aerospace Sciences, vol. 41, no. 1, pp. 1-28, 2005.

[11] J. H. Frieman, "Multivariate adaptive regression splines", The Annals of Statistics, vol. 19, no. 1, pp. 1-67, 1991.

[12] V. R. Tselykh, "Multidimensional adaptive regression splines", Mashinnoe obuchenie $i$ analiz dannyih, vol. 1, no. 3, pp. 272-278, 2012 [in Russian].

[13] A. G. Ivakhnenko, Inductive method of selforganization of models of complex systems. Kiev: Nauk. dumka, 1982 [in Russian].

[14] P. V. Afonin, and O. Yu. Lamskova, "Algorithms for optimization of simulation models of complex systems based on neural networks", Izvestiya YUFU: Tehnicheskie nauki, Themat. issue: Intellectual CAD, no. 12 (101), pp. 226-232, 2009 [in Russian].

[15] V. Ya. Halchenko, R. V. Trembovetska, and V. V. Tychkov, "The use of neurocomputing at the stage of metamodels development in the process of optimal surrogate antennas synthesis", Visnyk NTUU «KPI». Seriia Radiotekhnika. Radioaparatobuduvannia, no. 74, pp. 60-72, 2018 [in Ukrainian].

[16] R. V. Trembovetska, V. Ya. Galchenko, and V. V. Tychkov, "Methods of improving the accuracy of neural network metamodels of overhead eddy current converters for surrogate synthesis", in 2-nd Sci. Conf. with Internat. Participation Non-Destructive Testing in Context of the Associated Membership of Ukraine in the European Union (NDT-UA 2018) (Poland, Lublin, 15-19 Oct. 2018), Poland: USNDT, 2018, no. 2, pp. 47-49 [in Ukrainian]. 
R. V. Trembovetska, $P$ h. D. (Eng), associate professor,

V. Ya. Halchenko, Dr. Sc. (Eng), professor,

V. V. Tychkov, Ph. D. (Eng), associate professor,

A. V. Storchak, postgraduate student

Cherkasy State Technological University

Shevchenko blvd, 460, Cherkasy, 18006, Ukraine

\section{ESTIMATION OF ACCURACY OF NEURO-NETWORK METAMODELS OF SURFACE EDDY CURRENT PROBES}

For the problem of synthesis of an eddy current probe with a homogeneous sensitivity zone, its RBF-metamodels which have high computational efficiency are created. These metamodels can be used to design a probe with a given distribution of the density of eddy currents at testing points of the space located on the surface of the conductive object in the testing area of the probe. The excitation coil of a concentric surface eddy current probe is represented by an actuator which is powered by an alternating current and located above the testing object with constant electrophysical parameters. The obtained metamodels are checked for adequacy and informativeness on a complex of statistical indicators with an objective estimation of their statistical significance. At the approximation of the response surface, the computer experiment plan was used, namely, the multidimensional search space was filled with points generated by means of $L P_{\tau}$-sequences that were evenly located on the response surface. The reproducibility of the review surface is checked using the resulting metamodel throughout the modeling area. A reasonable approximation error has been achieved. The results of numerical experiments show the effectiveness of the use of RBF-metamodel for the response surface approximation. The resulting metamodels have an average model error of $6.76 \%$ for the first subregion, $4.8 \%$ for the second and $4.78 \%$ for the third one. Created metamodel is adequate according to Fisher criterion; informative on the coefficient of determination and significantly reliable. At the same time, it allows to reduce the workload of calculations in the tasks of computer designing of eddy current probes. This opens up new possibilities for the synthesis of surface eddy current probes - both parametric and structural-parametric ones.

Keywords: metamodel, response surface approximation, neural network, computer experiment plan, metamodel adequacy, metamodel informativity, eddy current probe, excitation coil, eddy current density.

Стаття надійшла 24.06.2019

Прийнято 26.07.2019

(C) Р. В. Трембовецька, В. Я. Гальченко, В. В. Тичков, А. В. Сторчак, 2019 DOI: 10.24025/2306-4412.2.2019.171272 